\title{
Martin Ebers
}

\section{Rechte, Rechtsbehelfe und Sanktionen im Unionsprivatrecht}

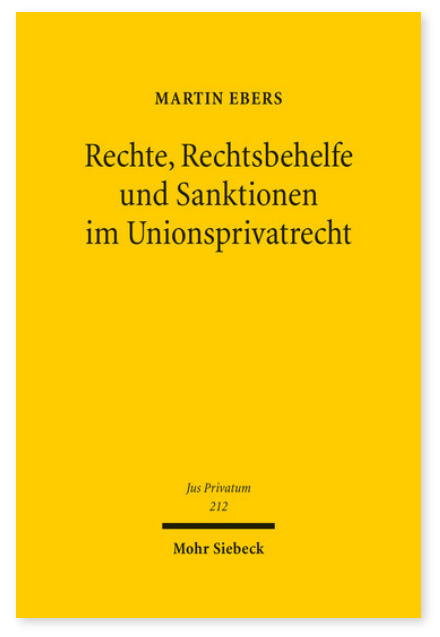

2016. LVI, 1116 Seiten. JusPriv 212

ISBN 978-3-16-154871-0

DOI 10.1628/978-3-16-154871-0

eBook PDF 194,00€

ISBN 978-3-16-154870-3

Leinen $194,00 €$
Obwohl viele Rechtsgebiete mittlerweile harmonisiert worden sind, regeln EU-Rechtsakte häufig nicht die Frage, welche Rechte, Rechtsbehelfe und Sanktionen zur Durchsetzung europäischen Rechts im nationalen Recht vorgesehen werden müssen. Andererseits ist zu beobachten, dass der EuGH den Schutz subjektiver (Unions-)Rechte schrittweise ausgebaut und ein eigenständiges Sanktionssystem aufgestellt hat, das intensiv in die mitgliedstaatlichen Rechtsordnungen eingreift und diese überlagert.

Martin Ebers entwickelt vor diesem Hintergrund eine allgemeine Theorie der im Unionsrecht wurzelnden (subjektiven) Rechte. Außerdem wird danach gefragt, wie ein Verstoß gegen Unionsnormen im nationalen (Privat-)Recht sanktioniert werden muss. Besonderes Augenmerk gilt dabei den Grundfreiheiten, dem Kartell- und Beihilferecht sowie dem Antidiskriminierungs- und Verbraucherrecht.

Martin Ebers Geboren 1970; Studium der Rechtswissenschaften und Philosophie an der FU Berlin; 2001 Promotion; Wissenschaftlicher Assistent an der WWU Münster; Forschung und Lehre in Barcelona, Budapest, Salamanca, Berlin; 2016 Habilitation an der HU-Berlin; seit 2015 Vertretungsprofessur an der Leibniz Universität Hannover und an der EuropaUniversität Viadrina Frankfurt (Oder).
Jetzt bestellen:

https://mohrsiebeck.com/buch/rechte-rechtsbehelfe-und-sanktionen-im-unionsprivatrecht-9783161548710?no_cache=1 order@mohrsiebeck.com

Telefon: +49 (0)7071-923-17

Telefax: +49(0)7071-51104 